\title{
Investigation of Mycoplasma agalactiae by molecular methods in goat bucks in West of Iran
}

\author{
Mohammad Khezri ${ }^{1, *}$, Seyed Ali Pourbakhsh², Abbas Ashtari², Babak Rokhzad ${ }^{1}$ \\ ${ }^{1}$ Department of Veterinary, Kurdistan Agricultural and Natural Resources Research Center, Kurdistan, Iran \\ ${ }^{2}$ Mycoplasma Reference Laboratory, Razi Vaccine \& Serum Research Institute, Alborz, Iran
}

Email address:

khezri1836@yahoo.com (M. Khezri),m.khezri@areo.ir (M. Khezri)

\section{To cite this article:}

Mohammad Khezri, Seyed Ali Pourbakhsh, Abbas Ashtari, Babak Rokhzad. Investigation of Mycoplasma agalactiae by Molecular Methods in Goat Bucks in West of Iran. Animal and Veterinary Sciences. Vol. 2, No. 6, 2014, pp. 218-222. doi: 10.11648/j.avs.20140206.20

\begin{abstract}
The presence of asymptomatic carriers of Mycoplasma agalactiae in goat buck populations, and the internal presence of this microorganism in some of these animals, indicated that the ability of this micro-organism captive in contagious agalactiae to colonize in other locations such as the respiratory system or genitalia. This study was designed to detect the excretion Mycoplasma agalactiae in goat bucks reared in Iran, where the disease is considered endemic. A total of 196 samples which included semen $(n=49)$, conjunctiva $(n=49)$, nasal $(n=49)$ and ear $(n=49)$ of goat bucks were collected from July to September 2013. To avoid the introduction of goat bucks carrying Mycoplasma organisms sub clinically in samples were obtained from all candidate goat bucks for PCR, to detect the presence of Mycoplasma agalactiae. Of the samples tested, $31.12 \%$ were scored positive for Mycoplasma spp. and Mycoplasma agalactiae was detected in seventeen samples, conjunctival ( 6 positive sample), nasal ( 1 positive sample), ear ( 5 positive sample) and semen ( 5 positive sample). The results obtained in the present study confirm of Mycoplasma agalactiae in the semen, conjunctival, nasal and ear in goat bucks without clinical symptoms of contagious agalactiae infection. The presence of this agent in male goat is considered very risky in terms of reproductive disorders and contagious agalactiae outbreaks in endemic areas in Iran. This is the first report of Mycoplasma agalactiae in goat bucks without contagious agalactiae signs in Iran.
\end{abstract}

Keywords: Contagious agalactia, Goat Bucks, Mycoplasma agalactiae, PCR

\section{Introduction}

Mycoplasma agalactiae (Ma) is the classical etiological agent of this disease which primarily affects goats and sheep along with many wild species. The impressive diffusion of antimicrobial therapies and adoption of very few prophylactic measures [1]. Ma was first reported, dates back in 1923 when Bridre and Donatien cultivated the microbe responsible for causing contagious agalactiae (CA) in goats for the first time [2]. CA is this disease is due to several factors including primitive herding practices, inefficiency a syndrome clinically characterized by mastitis, arthritis, keratoconjunctivitis and occasionally abortion[3] and $\mathrm{Ma}$ is considered its major etiological agent. M. mycoides subsp. capri (Mmc), M. capricolum subsp. capricolum (Mcc) and $M$. putrefaciens $(\mathrm{Mp})$ cause a clinically similar syndrome, particularly in goats [4]. The CA are reported from Mediterranean area, Balkan, south west Asia countries like Turkey, Iran, Iraq, center east of Africa, and united states of
America in endemic form[5-7]. It is very difficult to control its transmission from diseased to healthy ruminant, because of in-sanitation and a poor hygienic production of sheep and goat [8]. CA spreads by direct contact with infected animals and disseminated into the environment through the infected milk, contaminated milking equipment, ocular discharge and the hands of the milkers. Infected rams may be able to spread the infection venereally $[9,10]$. Interestingly, the significance of the different Mycoplasma species causing CA varies depending on the geographic area. In the United State and in Northern Jordan Mmc and Ma play the major role in both, sheep and goats [5,3]. In France, Ma has reemerged in sheep flocks [11]. In Iran, CA is endemic, characterized by agalactia, mastitis, arthritis, keratoconjunctivitis, sometimes abortion, and pneumonia and caused major economic losses $[12,13]$ and was reported for the first time in 1963 [14]. The presence of these microorganisms in the reproductive system of males has been associated with diseases such as orchitis, seminal vesiculitis, balanoposthitis, epididymitis and other functional disorders related to the morphology and motility 
of spermatozoa $[15,16]$. In chronically infected carriers, the presence of Ma and Mmc at sites other than the external ear canal has also been observed. Moreover, in one of these artificial insemination centers, in which $\mathrm{Ma}$ and $\mathrm{Mmc}$ were detected in conjunctival and preputial swabs, infection spread to the rest of the animals, confirming the fact that carriers actively participate in transmitting the disease [17]. Finally, the detection of $\mathrm{Ma}$ in the semen of naturally infected asymptomatic goat bucks also points to a real risk of venereal transmission[18]. Vaccines for the prevention of CA due to $\mathrm{Ma}$ are used widely in the Mediterranean countries of Europe and in western Asia. No single vaccine has been universally adopted, and no standard methods of preparation and evaluation have been applied [19]. In Iran, the disease has been controlled either by vaccination or antibiotic therapy. However, these strategies are not successful for prophylaxis or eradication program. Antibiotic therapy can result in symptomatic improvement, but treated animals may remain carriers due to antibiotic resistance, and inactivated vaccines generally provide short-term protection [20]. In Iran, programs based on a Ma inactivated vaccine have resulted in the reduction of clinical signs associated with CA outbreaks. In an endemic area with no described clinical outbreaks of caprine $\mathrm{CA}, \mathrm{Ma}$ and Mmc can be surveyed through PCR analysis of mastitis milk and balk tank milk (BTM) samples [21]. The first report of the isolation of Ma from the semen of asymptomatic carriers has recently been described [17]. This study was accordingly designed to detect the presence of carriers of Mycoplasmas causing CA in Markhoz goat bucks participating in the genetic improvement plan of the Ministry of Jihad-e-Agriculture, where male goats are used in genetic or breeding programmes.

\section{Materials and Methods}

\subsection{Sample Collection}

The study was performed during 5 month (from May to September) on 2 populations of goats reared in different areas of Iran, comprising a total of 196 animals. Bucks are checked for tuberculosis, paratuberculosis, contagious caprine pleuropneumonia, scrapie, brucellosis, bluetongue and CA. Prior to sample collection, the animals were clinically examined. No animal showed clinical symptoms of CA infection. To determine the presence of carriers of Ma, a total of 196 samples were collected from fresh semen $(n=49)$, conjunctival $(n=49)$, nasal $(n=49)$ and ear $(n=49)$ of goat bucks (Capra hircus) from July to September 2013. The fresh semen samples were collected from goat bucks of one age. Subsequently, semen samples were collected using the artificial vagina method. The samples (Semen moved in micro tubes without transport medium) were taken and immediately placed in the test tube with Mycoplasma culture transport medium (made by Hesarak, Razi Vaccine and Serum Research Institute of Iran), and stored at $4{ }^{\circ} \mathrm{C}$ till transport to Mycoplasma reference laboratory for PCR test within 24 hours. The transport medium contained thallous acetate $(250 \mathrm{mg} / \mathrm{liter})$ which toxic to some mycoplasma but not those causing CA and reduce the bacterial contamination [22].

\subsection{Polymerase Chain Reaction}

DNA was extracted from enriched samples using a previously described method [23]. In this method $500 \mu$ of samples were placed in $1 \times 5 \mu 1$ Eppendorf tube, micro centrifuged at $13,000 \mathrm{~g}$ for $15 \mathrm{~min}$. $100 \mu \mathrm{l}$ of lyses buffer was added to $100 \mu \mathrm{l}$ of precipitated, and tubes were placed in $56^{\circ} \mathrm{C}$ bath for $4 \mathrm{~h}$. Then $200 \mu \mathrm{l}$ saturated phenol was added and tubes was centrifuged at 13,000 g for 20min. Upper phase was transferred to another tube and equal volume of mixed Phenol/ Chloroform (1:1) was added. After centrifuged at $13,000 \mathrm{~g}$ for $20 \mathrm{~min}$ the aqueous phase was transferred to another tube and added equal volume of pure Chloroform and was centrifuged at $13,000 \mathrm{~g}$ for $5 \mathrm{~min}$. Upper phase was transferred to a new tube and mixed with $1 / 10$ volume of acetate sodium $(3 \mathrm{M})$ and were precipitated in $20^{\circ} \mathrm{C}$ refrigerator with 2 fold volume of cool and pure ethanol (20min), then the tube was centrifuged at $13,000 \mathrm{~g}$ for $15 \mathrm{~min} .200 \mu \mathrm{l}$ of ethanol $70 \%$ was added and the tube was centrifuged at $13,000 \mathrm{~g}$ for $5 \mathrm{~min}$, the DNA was dried and resuspended in DDW at $4^{\circ} \mathrm{C}$ and used for PCR[23]. In this study two primers (forward and reverse) amplify $163 \mathrm{bp}$ region of 16S rRNA gene of Mycoplasma genus[23] and amplify $375 \mathrm{bp}$ region of $16 \mathrm{~S}$ rRNA gene of Ma species[8]were used (Tab. 1). DNA amplification was carried out in a total volume of $35.25 \mu \mathrm{l}$ containing $17.5 \mu \mathrm{l}$ DNA, $0.1 \mu \mathrm{l}$ of each primer, $0.5 \mu \mathrm{l} \mathrm{dNTP} \operatorname{mix}(10 \mathrm{mM}), 4 \mu \mathrm{l} \mathrm{MgCl}_{2}$ $(25 \mathrm{mM}), 2.5 \mu \mathrm{l}$ PCR buffer $(10 \times)$, and $0.25 \mu \mathrm{l}$ Tag DNA polymerase $(5$ unit $/ \mu 1)$. Reaction mixture was thermo cycled (Bio-Rad, Hercules, CA, USA) 30 times at $94^{\circ} \mathrm{C}$. The temperature and time profile of each cycle was as following: $94^{\circ} \mathrm{C}$ for $1 \mathrm{~min}$ (Annealing) and $72^{\circ} \mathrm{C}$ for $1 \mathrm{~min}$ (Extension), PCRs were carried out using two program thermal cycler (primus and master gradient). Positive and negative controls were included in all tests. Each micro liter aliquot of each PCR products was mixed with $2 \mu$ l loading buffer $(6 \times)$. The PCR products and $100 \mathrm{bp}$ DNA ladder were then separated by electrophoresis on $1 \%$ agarose gels and stained with $0.5 \mu 1 / \mathrm{ml}$ ethidium bromide (100 volts for $1 \mathrm{~h})$ following UV trans illuminator (BioRad, Hercules, CA, USA). Sequences were aligned using MEGA 4.0 software [24].

Table1. Nucleotide sequences and primers used for identification of Ma by PCR

\begin{tabular}{|c|c|c|c|c|}
\hline Primer & Target gene & Sequence & Length(bp) & References \\
\hline FS1 & 16S rRNA & $\begin{array}{l}\text { F: 5'-GCTGCGGTGAATACGTTCT-3' } \\
\text { R: 5'-TCCCCACGTTCTCGTAGGG-3' }\end{array}$ & 163 & {$[23]$} \\
\hline FS2 & 16S rRNA & $\begin{array}{l}\text { F: 5'-AAAGGTGCTTGAGAAATGGC-3' } \\
\text { R: 5'-TTGCAGAAGAAAGTCCAATCA-3' }\end{array}$ & 375 & {$[8]$} \\
\hline
\end{tabular}




\section{Results}

In total, $61(31.12 \%)$ of the samples were positive for the presence of mycoplasmas by PCR (Fig.1).Ma was diagnosed from 17 samples (8.67\%) tested (Fig.2). These positive samples including 6 conjunctival swabs (12.24\%), 1 nasal swabs $(2.04 \%), 5$ ear swabs $(10.20 \%)$ and 5 semen samples $(10.20 \%)$. In the semen, mycoplasmas were the most detected with 36 samples proving positive for these microorganisms (73.46\%). The results are presented in Table 2 .

Table 2. Distribution of samples for Mycoplasma spp. and Ma in goat bucks.

\begin{tabular}{lccccc}
\hline & & \multicolumn{2}{c}{ Mycoplasma spp.-PCR } & \multicolumn{2}{c}{ Ma-PCR } \\
\cline { 3 - 6 } & & No. & $\%$ & No. & $\%$ \\
\hline Conjunctival swabs & 49 & 10 & 20.40 & 6 & 12.24 \\
Nasal swabs & 49 & 4 & 8.16 & 1 & 2.04 \\
Ear swabs & 49 & 11 & 22.44 & 5 & 10.20 \\
Semen & 49 & 36 & 73.46 & 5 & 10.20 \\
Total & 196 & 61 & 31.12 & 17 & 8.67 \\
\hline
\end{tabular}

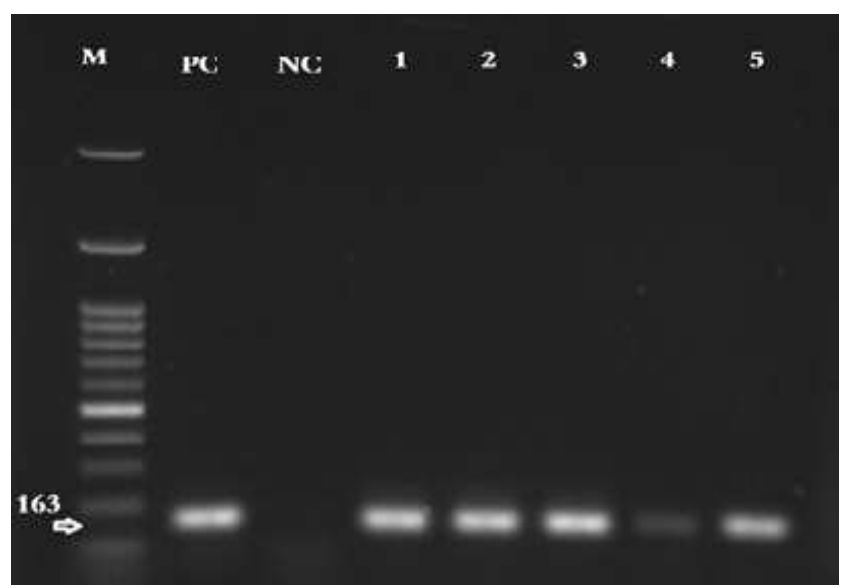

Figure 1. PCR products for Mycoplasma genus, Line M: Marker 100bp, Line PC: Positive Control, Line NC: Negative Control, Line1-5: positive samples.

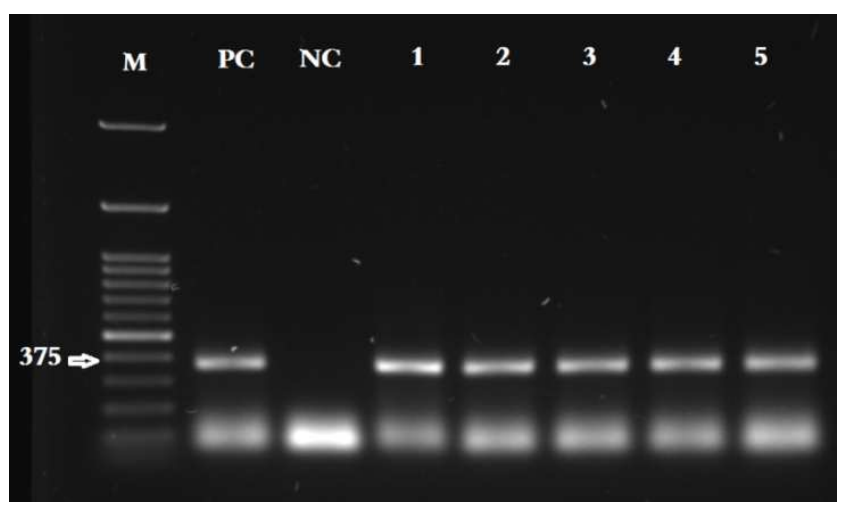

Figure 2. PCR products for Mycoplasma species, Line M: Marker 100bp, Line PC: Positive Control, Line NC: Negative Control, Line1-5: positive samples.

\section{Discussion}

In Iran, anti-Mycoplasma vaccines are used for small ruminant mycoplasmosis control that may reduce Ma infection. So for diagnosis of $\mathrm{CA}$ in a herd, the heamaglutination inhibition (HI), indirect immunoflourocense test (IFT), compliment fixation test (CFT) and ELISA tests are not very sensitive, on the other hand the serologic and bacteriologic methods may be useful to detect the species of Mycoplasma, while antibody titrations is very important to diagnose the diseases in the field. In most of the cases because of the negative results of serological test and the rapid spread of Mycoplasma in a herd, a quick, sensitive and specific method is required for detection of Mycoplasma infections. Therefore use of DNA probe has been reported for quick detection of Ma infection [25]. Although serological tests have been useful in screening programs, serology is not a suitable method in those areas, such as Iran, systematic vaccination is extended [4]. The presence of carriers of pathogenic and nonpathogenic Mycoplasmas in goat herds, including all species involved in CA, has been reported since the 1980s. However, their epidemiological role remains unclear although CA carriers have been related to new clinical outbreaks and CA entry or reemergence in free-herds $[26,27,6]$. The results provided the first evidence for shedding of $\mathrm{Ma}$, as the most important causal agent of CA syndrome, in the samples were collected of goat bucks herds that no showed clinical symptoms of CA infection. The number of samples scored positive for the Ma was high. As far as we are aware, however, no data exist on the surveillance of Ma in male goat herds in an endemic area. To date, Ma had been detected from purulent testicular exudates of experimentally infected bucks and rams [28,29] and in semen of naturally infected goat bucks[18]. Although up until now, no other Mycoplasma had been isolated from the semen of goats [18]. However, it is noteworthy that a similar frequency of isolation of $\mathrm{Ma}$ in goat bucks has not been recorded. This finding is in agreement with previous studies $[18,29]$. The potential role of males as a permanent reservoir of Mycoplasma spp. that could infect females via venereal transmission has been suggested $[18,30]$. The use of goats for semen collection is a normal practice and if venereal transmission is finally demonstrated, teaser doles could be easily infected by a buck excreting Mycoplasmas and then transmit the infection [26]. The risk of CA spread is further supported by the present findings indicating the presence of carriers in a high percentage of goat male populations used in reproductive programs and the sporadic presence of $\mathrm{Ma}$ in semen, confirming previous observations $[26,18]$. Although in Iran more than $90 \%$ of sheep and goats are kept together in mixed farms, contrary to expectations, no positive sample was observed in goats. In a survey on sheep and goat milk samples in Kurdistan Province, Ma was positive in five (1.3\%) out of 376 samples by culture and PCR and only one (20\%) out of 5 isolates was from goats[20]. Since both hosts (sheep and goats) are exposed to the same pathogens, it seems that Ma does not play the major role in CA in Iranian goats. In Iran, the importance of mycoplasmosis as a cause of reproduction failure in goats, functional alterations in the semen of goat 
bucks and the role of these asymptomatic buck goats in the development of CA is still unknown. No published references have been found to changes prompted by these Mycoplasma species in the genital tract. Ma has also been isolated from vulvovaginal lesions [31]. The high frequency detected in semen may be a risk factor for outbreaks of $\mathrm{CA}$ and reproductive disorders in regions of intensive goat breeding. Intensive goat breeding centers must be monitored in a program of mycoplasmosis control. The emergence of $\mathrm{CA}$ in non-infected herds has been almost always linked to the introduction of carriers of Mycoplasma spp., and the most common infection site is the external ear canal [6]. The peculiar features and risks of this carrier state determined that it may occur independently of any clinical expression [27]. Although the epidemiologic role played by asymptomatic carriers has not yet been fully elucidated, the possibility that they can transmit CA does seem clear $[6,17,1]$. These two unanswered questions regarding the epidemiology of $\mathrm{CA}$ are crucial for real control of the disease [32]. Thus, the presence of asymptomatic carriers means the health status of a herd cannot be truly known and there is a risk of subsequent propagation of the etiological agents [33]. In Iran, where live vaccines for $\mathrm{Ma}$ are not acceptable, attention has focused on the use of killed organisms, mostly using formalin and an adjuvant such as aluminum hydroxide in an oil emulsion, so that in endemic areas, in which all species are present, the animals are not protected against these other species. Live attenuated vaccines against Ma have been used in Turkey for many years and have been reported to provide better protection in ewes and their lambs than inactivated vaccines [34]. However, they can produce a transient infection with shedding of Mycoplasma. Live vaccines should not be used in lactating animals and should be part of a regional plan in which all flocks from which animals are likely to come into contact be vaccinated at the same time[19]. The use of inactivated CA vaccines in endemic areas has been reported to reduce the number of goats and kids developing clinical CA but fails to prevent natural infection $[35,21]$, and seems to indicate that current $\mathrm{CA}$ vaccines only serve to reduce clinical symptoms but not to prevent new infections or reduce the prevalence of infected animals within an infected herd[35]. Moreover, it shows that some animals in the vaccinated herd may shed Mycoplasmas in the semen and thus in theory poses a risk for any measures implemented to control the disease [18]. Earinfecting Mycoplasmas have also been detected in animals clinically affected during an outbreak of CA[1]. Hence, the successful diagnosis of carriers is essential so that appropriate control measures can be quickly installed[6]. CA is considered as a neglected disease of small ruminants because of the complex disease distribution pattern, ubiquitous nature of the causal agent and poor sheep and goat farm management practices, especially in developing and under developed countries like Iran. Rapid spread, multiple sources of infection along with vertical and horizontal mode of transmission are matter of immense concern and severely affect the local economy. Depending upon conditions like deprivation of maternal antibodies, immunocompromised state, stress due to transportation, pregnancy or extreme climatic conditions; animals may suffer from acute, sub-acute, chronic or asymptomatic forms of disease. Moreover, in CA endemic regions, the presence of asymptomatic carriers in a herd which carry the infectious agent is of major concern.

\section{Acknowledgements}

This work was supported by the Razi Vaccine and Serum Research Institute, Iran (Research Project 0-18-18-89067/8) and the Agricultural and Natural Resources Research Center of Kurdistan, Iran.

\section{References}

[1] Gil, M. C., Hermoso de Mendoza, M., Rey, J., Alonso, J. M., Hermoso de Mendoza, J., and Poveda, J. B. 1999. Aetiology of caprine contagious agalactica syndrome in Extreadura, Spain. The Veterinary record, 144, 24-25.

[2] Bridre, J., and Donatien, A. 1923. Le microbe de l'agalaxie contagieuse et sa culture In vitro. Comptes rendus de l'Académie des sciences, 177, 841-843.

[3] De la Fe, C., Assuncao, P., Antunes, T., Rosales, R. S., and Poveda, J. B. 2005. Microbiological survey for Mycoplasma spp. In a contagious agalactia endemic area. The Veterinary Journal, 170, 257-259.

[4] Ariza-Miguel, J., Rodríguez-Lázaro, D., and Hernández, M. 2012. A survey of Mycoplasma agalactiae in dairy sheep farms in Spain. BMC Veterinary Research, 8, 1-6.

[5] Al-Momani, W., Abo- Shehada, M. N., and Nicholas, R. A. J. 2011. Seroprevalence of and risk factors for Mycoplsma mycoides subspecies capri infection in small ruminants in Northern Jordan. Tropical Animal Health and Production, 43, 463-469.

[6] Corrales, J. C., Esnal c, A., De la Fe, C., S'anchez a, A., Assunc aob, P., Poveda, J. B., and Contreras, A. 2007. Contagious agalactia in small ruminants. Small Ruminant Research, 68, 154-166.

[7] Zendulkova, D., Madanat, A., and Lany, P. 2007. Detection of Mycoplasma agalactiae by Polymerase Chain Reaction in Jordanian Sheep and goat herds. Acta Veterinaria Brno, 76, $71-77$

[8] Tola, S., Angioi, A., Rocchigiani, A. M., Idini, G., Manunta, D., Galleri, G., and Leori, G. 1997. Detection of Mycoplasma agalactiae in sheep milk samples by polymerase chain reaction. Veterinary Microbiology, 54, 17-22.

[9] Mdanat, A., Zendulkov, D., and Posp, Z., 2001. Contagious agalactia of sheep and goats. A review. Acta Veterinaria Scandinavica, 70, 403-412.

[10] Al-Momani, W., Nicholas, R. A. J., and Abo-Shehada, M. N. 2008. Risk factors associated with Mycoplasma agalactiae infection of small ruminants in northern Jordan. Preventive Veterinary Medicine, 83, 1-10.

[11] Chazel, M., Tardy, F., Le Grand, D., Calavas, D., and Poumarat, F. 2010. Mycoplasmoses of ruminants in France: recent data from the national surveillance network. BMC Veterinary Research, 6, 1-8. 
[12] Hasani-Tabatabayi, A., and Firouzi, R. 2005. Disease of animals due to bacteria. Tehran: Tehran University Press.

[13] Khezri, M., Pourbakhsh, S. A., Ashtari, A., Rokhzad, B., and Khanbabaie, H. 2012. Isolation and prevalence of Mycoplasma agalactiae in Kurdish sheep in Kurdistan, Iran. Veterinary World, 5, 727-731.

[14] Borry, G., and Entessar, F. 1963. Etude sur 1 agalaxie contagieuse des chevres et des moutons. Archives of Razi Institute, 15, 45-63.

[15] Eaglesome, M. D., Garcia, M. M., and Stewart, R. B. 1992. Microbial agents associated with bovine genital tract infections and semen. Part II. Haemophilus sonnus,Mycoplasma spp., Ureaplasma spp. and Chlamydia, pathogens and semen contaminants: treatment of bull semen with antimicrobial agents. Veterinary Bulletin, 62, 887-910.

[16] Rizzo, H., Junior, E. B. S. M., Oliveira, R. C., Yamaguti, M., Buzinhani, M., Timenetsky, J., and Gregory, L. 2011. Mollicutes isolation and PCR on ovine vaginal mucous and its association with reproductive problems in Piedade, SP, Brazil. Ciência Rural, 41, 324-329.

[17] De la Fe, C., Gómez Martín, A., Amores, J., Corrales, J. C., Sánchez, A., Poveda, J. B., and Contreras, A. 2010. Latent infection of male goats with Mycoplasma agalactiae and Mycoplasma mycoides subsp. capri at an artificial insemination centre. The Veterinary Journal, 186, 113-115.

[18] De la Fe, C., Amores, J., Martin, A. G., Sanchez, A., Contreras, A., and Corrales, J. C. 2009. Mycoplasma agalactiae detected in the semen of goat bucks. Theriogenology, 72, 1278-1281.

[19] OIE. 2013. OIE Reference Laboratories for any further information on diagnostic tests, reagents and vaccines for contagious agalactia. In, Terrestrial Manual. International Office of Epizootics, pp. 1-9.

[20] Moradi Bidhendi, S., Khaki, P., and Pilehchian Langroudi, R. 2011. Isolation and identification of Mycoplasma agalactiae by culture and Polymerase Chain Reaction in Sheep and Goat Milk Samples in Kurdistan province, Iran. Archives of Razi Institute, 66, 11-16.

[21] De la Fe, C., Gutierrez, A., Poveda, J. B., Assuncao, P., Ramirez, A. S., and Fabelo, F. 2007. First isolation of Mycoplasma capricolum subsp. capricolum, one of the causal agents of caprine contagious agalactia, on the island of Lanzarote (Spain). The Veterinary Journal, 173, 440-442.

[22] Buonavoglia, D., Grecoa, G., Correntea, M., Grecoa, M. F., D'Abramoa, M., Latronicoa, F., Fasanellab, A., and Decaroa, N. 2010. Long-term immunogenicity and protection against Mycoplasma agalactiae induced by an oil adjuvant vaccine in sheep. Research in Veterinary Science, 88, 16-19.

[23] Kojima, A., Takahashi, T., Kijima, M., Ogikubo, Y., Nishimura, Y., Nishimura, S., Harasawa, R., and Tamura, Y. 1997. Detection of Mycoplasma in avian live virus vaccines by polymerase chain reaction. Biologicals, 25, 365-371.
[24] Tamura, K., Dudley, J., Nei, M., and Kumar, S. 2007. MEGA4 Molecular Evolutionary Genetics Analysis (MEGA) software version 4.0. Molecular Biology and Evolution, 24, 1596-1599.

[25] Pooladgar, A. R., Rahimilarki, E., Ghaem Maghami, S., Hossieni, S. M. H., and Ghaleh Golab, B. 2011. Application of PCR for diagnosis of contagious agalactia in Khuzestan Province-Iran. African Journal of Microbiology Research, 5, 5097-5101.

[26] Amores, J., Gomez-Martin, A., Corrales, J. C., Sanchez, A., Contreras, A., and De la Fe, C. 2011. Presence of contagious agalactia causing mycoplasmas in Spanish goat artificial insemination centers. Theriogenology, 75, 1265-1270.

[27] Bergonier, D., Berthelot, X., and Poumarat, F. 1997. Contagious agalactia of small ruminants: current knowledge concerning epidemiology, diagnosis and control. Revue Scientifique et Techchnique de l'office International Des Epizooties, 16, 848-873.

[28] Ak, K., Ak, S., Gurel, A., Hasoksuz, M., Barau, A., Ozturkeler, Y., Ileri, I. K., and Minbay, M. 1995. Experimental studies on the effects of Mycoplasma agalactiae on the spermatozoa and genital organs of rams. Pendik Veterinary Mikrobiyology, 26, 139-155.

[29] Hasso, S. A., AI-Aubaidi, J. M., and Al-Darraji, A. M. 1993. Contagious agalactia in goats: It's severity as related to the route of infection and pregnancy. Small Ruminant Research, $10,263-275$.

[30] Sylla, L., Stradaioli, G., Manuali, E., Rota, A., Zelli, R., Vincenti, L., and Monaci, M. 2005. The effect of Mycoplasma mycoides spp. Mycoides LC of bovine origin on in vitro fertilizing ability of bull spermatozoa and embryo development. Animal Reproduction Science, 85, 81-93.

[31] Singh, N., Rajya, B. S., and Mohanty, G. C. 1974. Granular vulvovaginitis (GVV) in goats associated with Mycoplasma agalactiae. Cornell Veterinary, 64, 435-442.

[32] Mercier, P., Pellet, M.-P., Morignat, E., Calavas, D., and Poumarat, F. 2007. Prevalence of mycoplasmas in external ear canal of goats: Influence of the sanitary status of the herd. Small Ruminant Research, 73, 296-299.

[33] Amores, J., Corrales, J. C., Martín, Á. G., Sánchez, A., Contreras, A., and de la Fe, C. 2010. Comparison of culture and PCR to detect Mycoplasma agalactiae and Mycoplasma mycoides subsp. capri in ear swabs taken from goats. Veterinary Microbiology, 140, 105-108.

[34] Nicholas, R. A. J. 2002. Improvements in the diagnosis and control of diseases of small ruminants caused by mycoplasmas. Small Ruminant Research, 45, 145-149.

[35] Amores, J., Sánchez, A., Gómez-Martín, A., Corrales, J. C., Contreras, A., and De la Fe, C. 2012. Surveillance of Mycoplasma agalactiae and Mycoplasma mycoides subsp. capri in dairy goat herds. Small Ruminant Research, 102, 8993. 